\title{
Selective Destruction of Nitric Oxide Synthase Neurons with Quisqualate Reduces Damage after Hypoxia-Ischemia in the Neonatal Rat
}

\author{
DONNA M. FERRIERO, R. ANN SHELDON, STEPHEN M. BLACK, AND JING CHUAI \\ Departments of Neurology [D.M.F., R.A.S., J.C.] and Pediatrics [D.M.F., S.M.B.], \\ University of California, San Francisco, San Francisco, California 94143-0114
}

\section{ABSTRACT}

The vulnerability of the developing CNS to hypoxia-ischemia $(\mathrm{H}-\mathrm{I})$ differs from that of the mature brain and is due in part to release of nitric oxide (NO) from parenchymal neurons. If NO is important in the generation of excitotoxic injury after H-I in the developing CNS, then selective destruction of the neuronal nitric oxide synthase (nNOS) cells before H-I should lessen the injury seen after the insult. Using low dose quisqualic acid (QA) injected into neonatal (postnatal d 7) parietal cortex, the nNOS neurons were eliminated while sparing other neuronal and glial populations as ascertained by NADPH diaphorase histochemistry, nNOS immunocytochemistry, and Nissl counterstain. Animals subjected to focal ischemia followed by global hypoxia 24 $\mathrm{h}$ after the intracortical injection of QA had more viable cortex remaining than vehicle-injected animals $(83.4 \pm 4.3 \%$ versus $62.7 \pm 8.3 \%$ ) and lower injury severity represented by less neuronal loss and gliosis. Intracortical injections of QA without $\mathrm{H}-\mathrm{I}$ resulted in minimal cell loss at the injection site with elimination of nNOS neurons throughout the parietal cortex.
Microglial and astrocytic proliferation was seen in areas damaged by $\mathrm{H}-\mathrm{I} 3 \mathrm{wk}$ after injury and clearly marked infarcted areas. Prevention or elimination of NO production from nNOS cells can prevent much of the delayed neuronal necrosis seen after H-I in the developing CNS. (Pediatr Res 38: 912-918, 1995)

$\quad$ Abbreviations
NMDA, $n$-methyl-D-aspartate
NO, nitric oxide
NOS, nitric oxide synthase
nNOS, neuronal nitric oxide synthase
NADPHd, nicotinamide adenine dinucleotide phosphate
diaphorase
QA, quisqualic acid
GFAP, glial fibrillary acidic protein
H-I, hypoxia-ischemia
HSP, heat shock protein
P7, postnatal day 7

The H-I encephalopathy seen in survivors of perinatal asphyxia represents the most common cause of static encephalopathies in infants and children (1). Excitatory neurotransmitters such as glutamate participate in brain damage caused by hypoxia and ischemia, and the neuropathologic effects of ischemia can be attenuated by antagonists effective at a specific subclass of glutamate receptors, the NMDA receptor (2).

Recent experiments suggest a role for NO in modulating glutamate neurotoxicity. It has been shown that, in primary cerebral cortical cell culture, glutamate neurotoxicity can be prevented by L-nitroarginine, an inhibitor of NO production (3). In coronal slices of mature rat brain incubated with NMDA, preincubation with L-nitroarginine attenuates the toxicity of NMDA (4). Therefore, the neurotoxicity associated

Received March 27, 1995; accepted June 23, 1995

Correspondence: Donna M. Ferriero, M.D., Department of Neurology, Box 0114 , University of California, San Francisco, San Francisco, CA 94143-0114.

Supported in part by a grant to D.M.F. from University of California Research Evaluation and Allocation Committee Mainprice Fund. with cerebral ischemia appears to involve glutamatergic stimulation of NO production via NMDA receptors. A subpopulation of neurons has been shown to contain a constitutive NOS, called nNOS, and in the setting of H-I, nNOS is activated by increased intracellular calcium (5). The increased NOS activity results in large amounts of NO diffusing out of the nNOS neuron to form reactive oxygen intermediates that kill nearby cells (6). Recently, it has been shown that, in adult mice deficient in nNOS, infarct size is reduced after middle cerebral artery occlusion (7).

nNOS mRNA and immunoreactivity has been localized in the rat brain to a distinct, small subpopulation of neurons previously identified as NADPHd-containing neurons (8). Interestingly, these NADPHd-positive, nNOS-immunoreactive neurons are relatively resistant to NMDA-mediated cell death. In murine cortical cell cultures derived from embryonic rat brain, exposure to quinolinate (an NMDA agonist) kills most neurons, but NADPHd-reactive neurons are spared (9). In a model of $\mathrm{H}-\mathrm{I}$ in infant rats, these neurons are selectively 
preserved after ischemic cell death and NMDA agonist injection (10). After the postnatal period, the selective resistance of these cells to ischemia progressively diminishes (11).

Despite their selective resistance to NMDA, the NADPHd/ NOS neurons are more susceptible than other neurons to kainate or QA toxicity $(11,12)$. Low concentrations of QA kill NADPHd-containing neurons without producing general neuronal injury in murine cortical neuronal culture. High doses of any glutamate agonist, on the other hand, will produce nonselective neuronal injury. The differential susceptibility of NADPHd/NOS-positive neurons to glutamate agonists provides a method for selectively eliminating the NOS-containing neurons.

The regional vulnerability of the developing brain to H-I damage is different from that of the adult brain. For example, perinatal asphyxia in the term infant is more likely to damage basal ganglia and deep layers of the cortex. The transient excess of glutamate receptors in these areas in the developing brain correlates well with the injury (13), and the selective expression of nNOS occurs temporally in regions that parallel glutamate receptor abundance (Black SM, Bedouilli M, Soifer $\mathrm{S}$, Bristow J, Ferriero DM, unpublished observations). It is conceivable that the relative resistance of NOS-containing neurons to NMDA-mediated injury in the neonatal brain contributes to the greater susceptibility of the immature brain in these areas by supporting excessive production of the neurotoxic molecule NO upon stimulation with glutamate. We therefore investigated the importance of $\mathrm{NO}$ in the pathogenesis of $\mathrm{H}-\mathrm{I}$ brain injury in the developing rat brain. We used the susceptibility of nNOS-containing neurons to low concentrations of QA to selectively eliminate these neurons before subjecting animals to a H-I insult. Our results support the hypothesis that NO generated by nNOS-containing neurons significantly contributes to H-I brain damage in this model.

\section{METHODS}

Seven litters of Sprague-Dawley rats were culled to 10 pups each and used for the following experiments on postnatal $\mathrm{d} 7$. All animal research was approved by the University of California San Francisco Committee on Animal Research and was performed with the highest standards of humane care as set forth in the Guide for the Care and Use of Laboratory Animals, U.S. Department of Health and Human Services, 85-23, 1985. Animals were divided into vehicle injection only (1 per litter), QA injection only (1 per litter), vehicle injection plus H-I (4 per litter), and QA injection plus H-I (4 per litter). Intraparenchymal injections with either QA, $10 \mathrm{nmol}$ in $0.1 \mathrm{M}$ phosphate buffer, $\mathrm{pH} 7.4$, or vehicle in a volume of $0.5 \mu \mathrm{L}$ were administered stereotactically into the right parietal cortex. H-I insult was produced $24 \mathrm{~h}$ after stereotactic injection of QA or vehicle (14). Animals were anesthetized with $1 \%$ halothane in $\mathrm{NO} /$ oxygen/nitrogen and the right carotid artery was coagulated, followed by a 2-h period when the pups were returned to the dam to nurse and recover from the anesthetic. Then animals were placed in containers in a water bath at $37^{\circ} \mathrm{C}$ and exposed to $2.5 \mathrm{~h}$ of hypoxia (humidified $8 \% \mathrm{O}_{2} / 92 \% \mathrm{~N}_{2}$ ).
In one litter of P7 pups, animals were subjected to topical infusion of $100 \mathrm{mM} \mathrm{KCl}$ to the right parietal cortex to stimulate spreading depression $(15,16)$. Using a blocked design, animals received either $\mathrm{KCl}$ or saline $24 \mathrm{~h}$ before $\mathrm{H}-\mathrm{I}$.

Three weeks later, all surviving animals were killed by pentobarbital euthanasia and perfused through the left ventricle with $4 \%$ paraformaldehyde in $0.1 \mathrm{M}$ phosphate buffer, $\mathrm{pH}$ 7.4. Brains were removed and immersed in the same fixative for 4 $\mathrm{h}$ and transferred to $30 \%$ sucrose in $0.1 \mathrm{M}$ phosphate buffer, $\mathrm{pH}$ 7.4. Forebrain sections were cut on a vibratome at $50-\mu \mathrm{m}$ intervals, and alternate sections were reacted for Nissl substance, NOS immunoreactivity or NADPHd histochemistry, and microglia (Ox42) and astroglia (GFAP) markers.

Briefly, the NADPHd histochemical method employs a 2-h incubation at $37^{\circ} \mathrm{C}$ in a solution containing $0.1 \mathrm{M}$ Tris- $\mathrm{HCl}(\mathrm{pH}$ 8), $0.2 \mathrm{mM}$ NADP, $15 \mathrm{mM}$ sodium malate, $0.2 \mathrm{mM}$ nitro blue tetrazolium, $1 \mathrm{mM} \mathrm{MnCl} 2$, and $0.1 \%$ Triton X-100 (10). NOS was localized immunohistochemically with an antibody specific for nNOS (gift of Dr. S. Black, University of California, San Francisco) at 1:3000 for $24 \mathrm{~h}$ at $4^{\circ} \mathrm{C}$. Microglia were localized with antibody to Ox42 (Serotec-MCA 275) at 1:4000 dilution for $2 \mathrm{~h}$ at $23^{\circ} \mathrm{C}$. Astrocytes were localized with antibody to GFAP (Peninsula) at 1:3000 dilution for $2 \mathrm{~h}$ at $23^{\circ} \mathrm{C}$. All immunocytochemistry was performed as previously reported using the $\mathrm{ABC}$ method (Vector Labs, Burlingame, CA) (17). Elimination of the primary antibody served as the control. All sections were mounted onto gelatinized slides, dehydrated, and coverslipped with Depex (Biomedical Specialties, St., Monica, CA).

Brain infarction was determined by two independent methods, by scoring brains histopathologically and by computing preserved ipsilateral hemispheric area relative to the noninvolved contralateral hemisphere. Histopathologic scoring of cresyl violet stained coronal sections was done blindly using a scale such that $0=$ no injury, $1=$ minimal cell loss manifested by scattered shrunken neurons and glia, $2=$ moderate cell loss with infarction in a columnar distribution in the cortex with concomitant gliosis, 3 = severe cell loss and gliosis with cystic infarction. Brain area was measured in coronal slices through the forebrain at the level of the anterior commissure using a video image analysis computerized system (Macintosh; $\mathrm{Na}-$ tional Institutes of Health Image 1.41), and the remaining area of the ipsilateral side was expressed as percent area of the contralateral uninvolved hemisphere. NADPHd cell loss was examined from identical sterotaxic planes in each animal in the same manner as for calculation of brain area.

Statistics were performed using analysis of variance with post hoc tests for continuous data and $\chi^{2}$ analysis for categorical data.

\section{RESULTS}

Injection of either vehicle or low dose QA into the P7 rat cortex resulted in a mild scar associated with neuronal loss restricted to the needle track and a small astroglial reaction around the injection site (Fig. 1, $A$ and $B$ ). There was complete loss of NADPHd-containing (nNOS) neurons throughout the parietal cortex after QA injection (Fig. 1D), but not after 

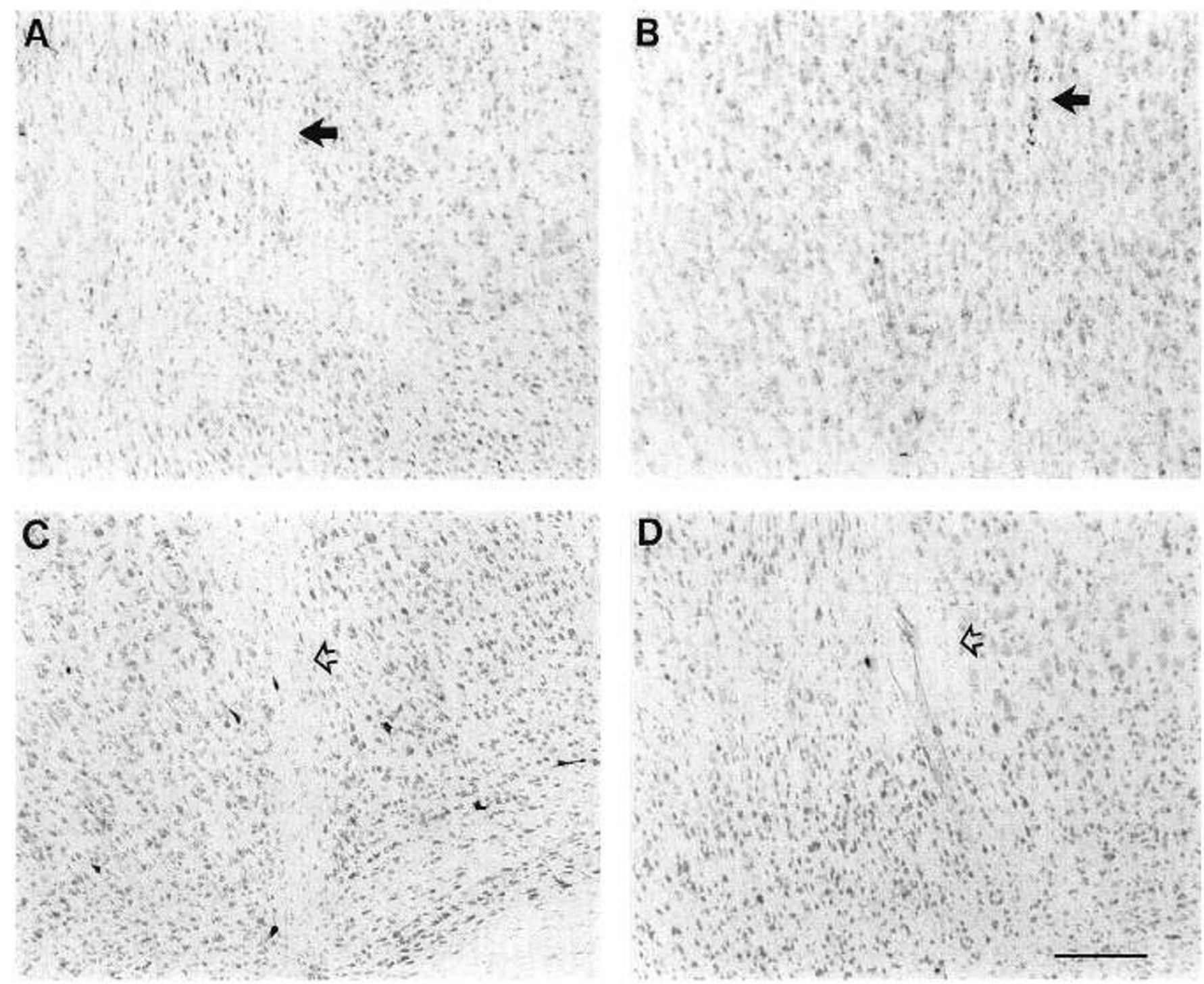

Figure 1. (A) Nissl-stained injection site of vehicle injected rat cortex in P7 animal showing scar (arrow) where the needle caused a small amount of neuronal loss. (B) Nissl-stained section of injection site in QA-injected rat cortex showing scar (arrow) where slight hemorrhage and neuronal cell loss has occurred. (C) Nissl and NADPHd-counterstained section through the same region as in $A$ showing scar and preservation of nNOS cells in region of injection and ipsilateral cortex. $(D)$ Nissl and NADPHd-counterstained section through the same regions in $B$ showing no surviving diaphorase cells after QA injection. There is one degenerating nNOS cell in this field (open arrow). Scale bar $=100 \mu \mathrm{m}$.

injection of the vehicle (Fig. 1C). Confirmation of loss of the nNOS immunoreactive cells was evident by immunocytochemistry in the cortex with the normal distribution of these cells seen in the striatum or in the cortex of vehicle injected animals (Fig. 2). Nissl counterstain revealed no substantial neuronal loss in the area devoid of NADPHd/NOS neurons except at the superficial injection site (Fig. 1), and there was no loss of brain area in the QA-injected cortices compared with vehicle-injected brains (Table 1).

After H-I injury, the vehicle-injected animals more often had profound injury with cystic infarction (Fig. 3C). Vehicleinjected animals had the same distribution of injury as animals with H-I alone without prior injection. Animals who were pretreated with intracortical QA $24 \mathrm{~h}$ before induction of the H-I were more likely to suffer only mild to moderate injury (Fig. 3, $A$ and $B$ ) in the cortex, and their histopathologic injury score was significantly lower than that of animals preinjected with vehicle (Table 1). Brain area after infarction was likewise significantly preserved in the QA-pretreated animals compared with vehicle-treated controls (Table 1). Animals receiving $\mathrm{KCl}$ infusion $24 \mathrm{~h}$ before $\mathrm{H}-\mathrm{I}$ to stimulate spreading depression suffered the same degree of brain injury as vehicle-infused animals.

The brains of injured animals showed a microglial reaction in the ipsilateral cortex that provided an excellent marker for the areas typically seen with this form of injury, i.e. there was a laminar distribution involving layers II-IV with intense microglial staining in a columnar pattern in the cortex with a patchy distribution in the dorsolateral striatum (Fig. 4, $C$ and $D$ ). This staining pattern correlated well with severity of injury seen histopathologically on Nissl stain and was more intense in the animals preinjected with vehicle than in the animals preinjected with QA when the injury was more severe. QA or vehicle injections alone did not cause a microglial reaction. 


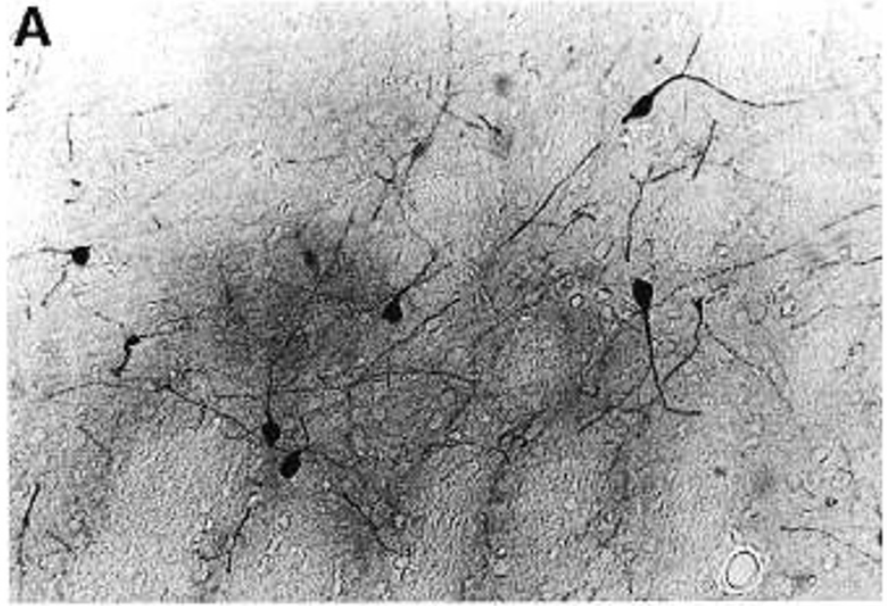

Table 1. Cortical injury after $H-I$ insult in $P 7$ rat

\begin{tabular}{lcc}
\hline \multicolumn{1}{c}{ Treatment } & Injury score & Brain area* \\
\hline Vehicle injection only $(n=9)$ & 0 & $98.9 \pm 0.7$ \\
QA injection only $(n=8)$ & 0 & $100.2 \pm 1.0$ \\
HI + vehicle $(n=20)$ & $1.61 \pm 0.33 \dagger$ & $62.7 \pm 8.3 \ddagger$ \\
HI + QA $(n=22)$ & $0.96 \pm 0.19 \dagger$ & $83.4 \pm 4.3 \ddagger$ \\
\hline
\end{tabular}

* Brain area expressed as percent ipsilateral/contralateral cortex $\times 100$; all values expressed as $X \pm \mathrm{SEM}$.

$\dagger p<0.0001$ by coded $\chi^{2}$ analysis for categorical data.

$\ddagger p=0.0002$ by analysis of variance with differences between treatments significant at $95 \%$ confidence interval by Fisher and Scheffe post hoc tests.
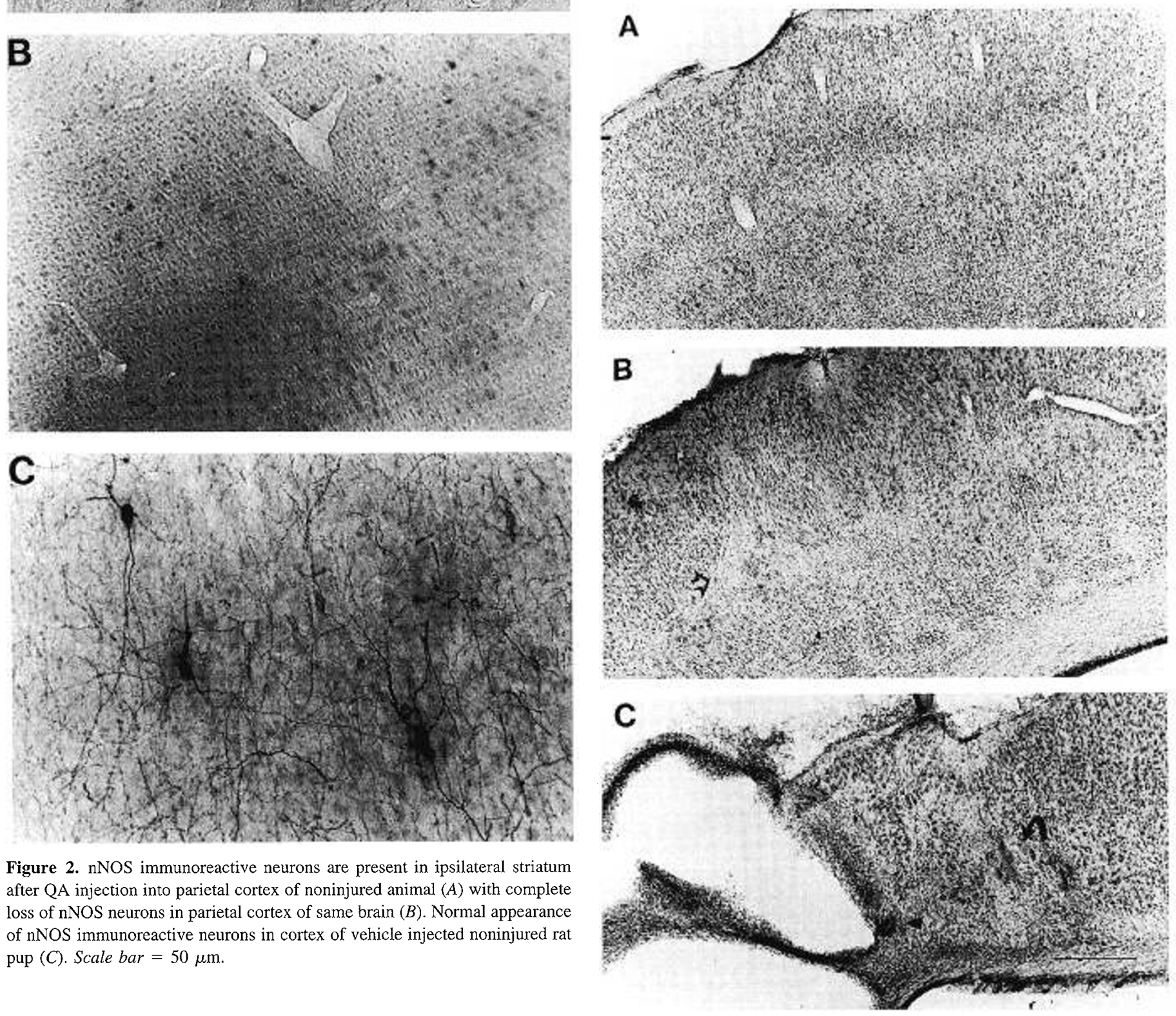

Figure 2. nNOS immunoreactive neurons are present in ipsilateral striatum after QA injection into parietal cortex of noninjured animal $(A)$ with complete loss of nNOS neurons in parietal cortex of same brain $(B)$. Normal appearance of nNOS immunoreactive neurons in cortex of vehicle injected noninjured rat pup $(C)$. Scale bar $=50 \mu \mathrm{m}$.

Astrocytic proliferation visualized with GFAP immunocytochemistry paralleled that seen in regions demonstrating microglial infiltration (Fig. 4, $A$ and $B$ ). The ipsilateral hippocampus was especially rich in GFAP immunoreactivity in all animals with moderate to severe injury (Fig. $4 A$ ).

Figure 3. The three patterns of injury seen after H-I. Ipsilateral cortex of QA-injected animal 3 wk after H-I shows only minimal neuronal loss and gliosis $(A)$ or in another QA-injected animal after H-I injury a moderate degree of damage with columnar infarction $(B)$. Severe gliosis and cystic infarction is seen in vehicle-injected animal after H-I (C). Arrowhead marks area of petechial hemorrhage next to a large cystic infarction, and curved arrow shows infarcted area around vehicle injection site. Scale bar $=250 \mu \mathrm{m}$. 

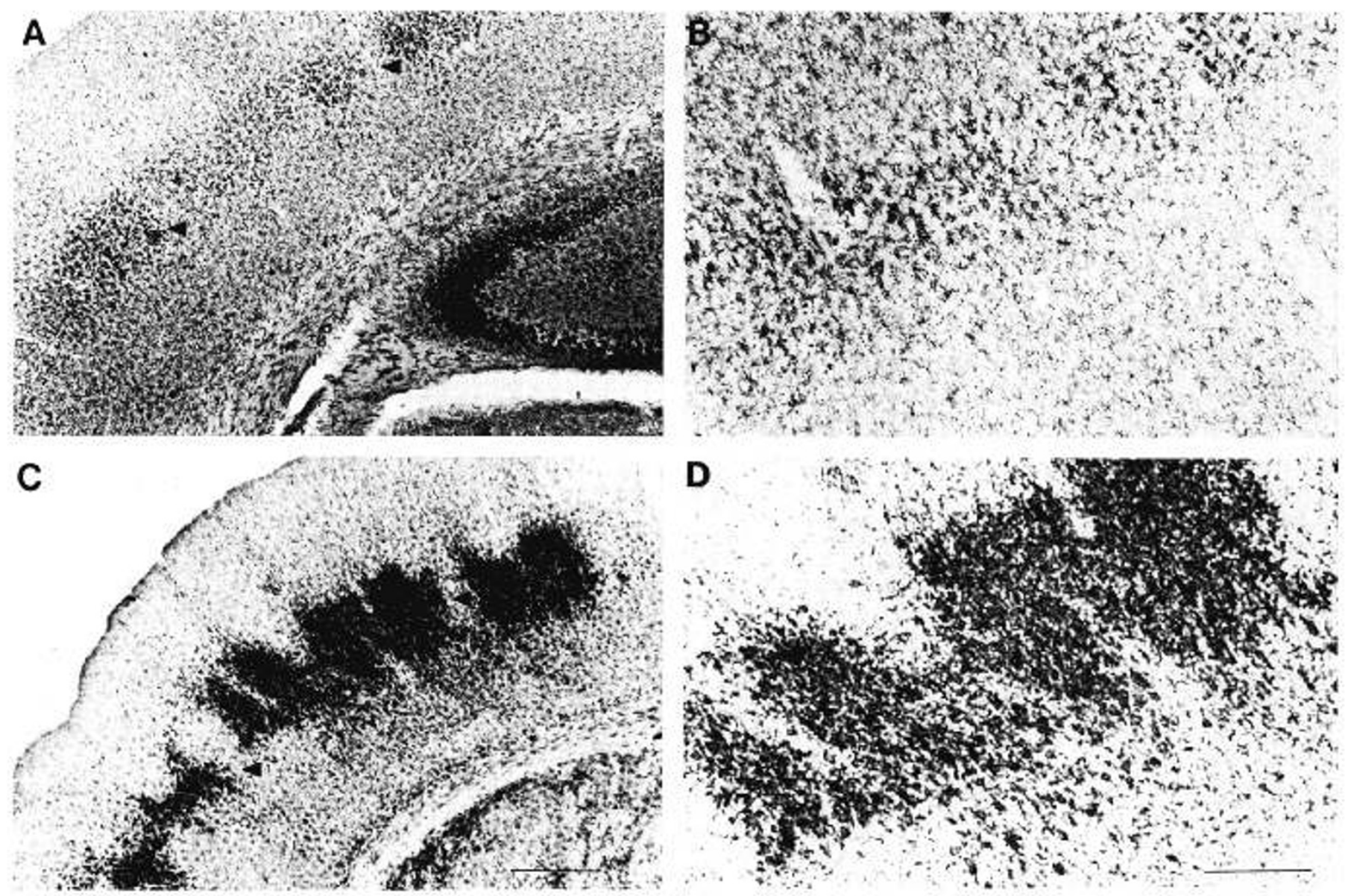

Figure 4. Coronal section of ipsilateral cortex of QA-injected animal $3 \mathrm{wk}$ after $\mathrm{H}-\mathrm{I}$ shows astrocytic proliferation in areas of columnar infarction and in the ipsilateral dorsal hippocampus $(A)$. Higher magnification of the area between arrowheads in $A$ depicts morphology of GFAP cells in deep layers of the cortex $(B)$. Alternate section of the same brain reveals intense microglial proliferation in similar areas of infarction in the cortex and dorsolateral caudate $(C)$. Higher magnification of area between arrowheads in $C$ depicts morphology of Ox42 immunoreactive cells and fibers $(D) . S c a l e$ bar for $A$ and $C=250 \mu$ m; scale bar for $B$ and $D=50 \mu \mathrm{m}$.

\section{DISCUSSION}

Our results support the hypothesis that NO is a critical mediator of damage in the developing CNS. Local elimination of the nNOS-containing neurons by intracortical injection of low dose QA in P7 rat cortex resulted in significant attenuation of the damage after H-I. There is accumulating evidence that NO is an important mediator of the neurotoxicity seen after excitatory amino acid release, especially in the setting of H-I injury. Using a mouse with targeted disruption of the gene for nNOS, Huang et al. (7) were able to show reduced cerebral injury in the knock-out mouse. In primary cortical cultures, NOS neurons appear to be the source of neurotoxic NO, and elimination of these neurons with $20 \mu \mathrm{M}$ QA diminish subsequent NMDA neurotoxicity (18). These data are in agreement with our observation that selective elimination of NOScontaining neurons can prevent much of the damage caused by $\mathrm{H}-\mathrm{I}$ in the developing nervous system.

The interactions between glutamate and NO in generating neurotoxicity have been elucidated by a number of recent studies. In primary cerebral cortical cell culture, glutamate neurotoxicity can be prevented by L-nitroarginine, a NOS inhibitor; and $\mathrm{Hb}$, which complexes $\mathrm{NO}$, prevents the neurotoxic effects of NMDA $(3,18)$. NMDA receptor activation stimulates NO formation in NOS neurons, but these neurons are selectively resistant to NMDA neurotoxicity. It is unclear why the neurons that generate NO are not susceptible to its destructive effects. Recent evidence suggests that, in the setting of H-I, NOS is induced in neurons by increased intracellular calcium after it binds to calmodulin (3). The increased NOS activity results in large amounts of NO diffusing out of the neuron into the extracellular space where it can combine with superoxide anion to form peroxynitrite. The generation of this neurotoxic species results in lipid peroxidation and cytotoxicity to nearby cells (6).

This information also helps to clarify the role of NO in H-I because there have been conflicting reports regarding protection against this form of injury in different models using nonselective blockers of NOS. Some of the differences observed between models of global and focal ischemia may be due to differential activation of various NOS enzymes in endothelium, neurons, astrocytes, and microglia. When endothelial and nNOS are inhibited simultaneously in the setting of $\mathrm{H}-\mathrm{I}$, damage reduction is unpredictable and can often be worse (19) if endothelial NOS is inhibited sufficiently to prevent adequate cerebral perfusion (7). In two focal models of H-I in the neonatal rat, NOS inhibitors reduce the injury in brain $(20$, 
21). In a model of global ischemia produced by repeated episodes of umbilical cord occlusion in fetal sheep, there is preferential damage to the striatum, suggesting that the damage is due to "excitotoxic" mechanisms (22). The use of NO inhibition in this model will yield critical information regarding the importance of NO toxicity in models of global ischemia to the developing brain.

It has previously been shown by us and others $(11,12)$ that the NADPHd neurons are a distinct subpopulation of neurons that have a unique profile of sensitivity to excitatory amino acids that changes during development. In vitro, these neurons become resistant to NMDA toxicity as they express NOS/ NADPH reactivity and at the same time are uniquely sensitive to low doses of the non-NMDA glutamate receptor toxin QA. The neonatal brain is remarkable in this regard because the relative sparing of the NOS/NADPHd neurons is lost after the second postnatal week (11). The relative resistance to the neurotoxic effects allows the NOS-containing neurons to continue producing NO in the setting of NMDA receptor activation associated with $\mathrm{H}-\mathrm{I}$ insult. The resultant $\mathrm{NO}$ can then combine with other free radicals such as superoxide to form unstable intermediates such as peroxynitrite that can contribute to cell death through lipid peroxidation, enzyme deactivation, and DNA nitration (6).

An alternative explanation for the decreased damage after intracortical QA injection in the setting of H-I may be the activation of spreading depression currents that protect the brain from further acute insults. Spreading depression is a transient phenomenon characterized by drastic depolarization of neurons and is accompanied by changes in blood flow and metabolism (23). In the adult brain, spreading depression provoked by nonhypoxic stimuli such as mechanical, chemical or electrical stimuli, does not induce irreversible neuronal injury in an otherwise normal brain, despite glutamate release and lactate accumulation (24). To eliminate the possibility that spreading depression provoked by QA administration protected the $\mathrm{H}-\mathrm{I}$ neonatal rat brain, animals received high dose $\mathrm{KCl}$ instead of QA before the H-I. There was no indication that activation of spreading depression changed the course of the injury in these animals.

A third possibility is that QA injection before the H-I insult caused a stress response with induction of heat shock/stress proteins which would protect cells from further injury. Simon et al. (25) have shown that repeated brief global H-I episodes can prevent damage to the mature rat CNS caused by subsequent focal ischemia and that these animals exhibit HSP72 production in areas of the cortex that were protected from the focal ischemic injury. It is unlikely that a single dose of QA would cause sufficient HSP induction to protect the brain from subsequent insult. In fact, in the neonatal animal, even hyperthermic insult enough to cause global HSP production does not protect the brain from future H-I (Ferriero DM, unpublished observations). In fact, we have shown HSP immunoreactivity in areas of $\mathrm{H}-\mathrm{I}$ damage in this model within $24 \mathrm{~h}$ of $\mathrm{H}-\mathrm{I}$ which did not correlate with areas later spared from neuronal loss (17).

Finally, the effect of QA pretreatment could relate to receptor-mediated activation of the metabotropic glutamate receptor instead of its direct action on elimination of the nNOS containing cells in the cortex. In murine cortical cultures and in adult mouse brain $(26,27)$ activation of the metabotropic receptor with ACPD (trans-1-aminocyclopentyl-1,3-dicarboxylic acid) attenuated cell loss due to NMDA activation or $\mathrm{H}-\mathrm{I}$. It is unlikely, however, that receptor activation continued $24 \mathrm{~h}$ after the single injection of QA.

In summary, we have shown that elimination of cortical NOS/NADPHd containing neurons $24 \mathrm{~h}$ before H-I injury protects the immature rat brain from severe damage. These results support a role of glutamate-induced release of nitric oxide as a mechanism of neuronal loss seen after this form of injury. Therapies aimed at reducing NO production selectively from neurons in the neonatal brain may be of value in ameliorating the damage after H-I.

Acknowledgments. The authors thank Drs. Martin G. Taeuber, Ray Swanson and Stephen M. Sagar for helpful discussions and Dr. Taeuber for review of the manuscript.

\section{REFERENCES}

1. Brann A 1985 Factors during neonatal life that influence brain disorders. In: Freeman J (ed) Prenatal and Perinatal Factors Associated with Brain Disorders (NIH Publican tion No. 85-1149). U.S. Government Printing Office, Washington, DC, pp 263-359

2. Meldrum BS, Evans MC, Swan JH, Simon RP 1987 Protection against hypoxic/ ischaemic brain damage with excitatory amino acid antagonists. Med Biol 65:153157

3. Dawson V, Dawson T, London E, Bredt D, Snyder SH 1991 Nitric oxide mediates glutamate neurotoxicity in primary cortical cultures. Proc Natl Acad Sci 88:63616371

4. Kalleger H, McBean G, Tipron K 1993 Reduction of striatal n-methyl-D-aspartate toxicity by inhibition of nitric oxide synthase. Biochem Pharmacol 45:260-264

5. Dawson TM, Dawson VL, Snyder SH 1992 A novel neuronal messenger molecule in brain: the free radical, nitric oxide. Ann Neurol 32:297-311

6. Beckman J 1991 The double-edged role of nitric oxide in brain function and superoxide-mediated injury. J Dev Physiol 15:53-59

7. Huang Z HP, Panahian N, Dalkara T, Fishman MC, Moskowitz MA 1994 Effects of cerebral ischemia in mice deficient in neuronal nitric oxide synthase. Science 265:1883-1885

8. Bredt DS, Glatt CE, Hwang PM, Fotuhi M, Dawson TM, Snyder SH 1991 Nitric oxide synthase protein and mRNA are discretely localized in neuronal populations of the mammalian CNS together with NADPH diaphorase. Neuron 7:615-624

9. Koh JY, Peters S, Choi DW 1986 Neurons containing NADPH-diaphorase are selectively resistant to quinolinate toxicity. Science 234:73-76

10. Ferriero DM, Arcavi LJ, Sagar SM, McIntosh TK, Simon RP 1988 Selective sparing of NADPH-diaphorase neurons in neonatal hypoxia-ischemia. Ann Neurol 24:670676

11. Ferriero DM, Arcavi LJ, Simon RP 1990 Ontogeny of excitotoxic injury to nicotinamide adenine dinucleotide phosphate diaphorase reactive neurons in the neonatal rat striatum. Neuroscience $36: 417-424$

12. Koh JY, Choi DW 1988 Vulnerability of cultured cortical neurons to damage by excitotoxins: differential susceptibility of neurons containing NADPH-diaphorase. J Neurosci 8:2153-2163

13. Greenamyre T, Penney JB, Young AB, Hudson C, Silverstein FS, Johnston MV 1987 Evidence for transient perinatal glutamatergic innervation of globus pallidus. J Neurosci 7:1022-1030

14. Rice JE, Vannucci RC, Brierley JB 1981 The influence of immaturity on hypoxicischemic brain damage in the rat. Ann Neurol 9:131-141

15. Kraig R, Dong L, Thisted R, Jaeger CB 1991 Spreading depression increases immunohistochemical staining of glial fibrillary acidic protein. J Neurosci 11:21872193

16. Moskowitz MA, NK, Kraig RP 1993 Neocortical spreading depression provokes the expression of c-fos protein-like immunoreactivity within trigeminal nucleus caudalis via trigeminovascular mechanisms. J Neurosci 13:1167-1177

17. Ferriero DM, Soberano H, Simon RP, Sharp FR 1990 Hypoxia-ischemia induces heat shock protein-like (HSP72) immunoreactivity in neonatal rat brain. Dev Brain Res 53:145-160

18. Dawson VL, Dawson TM, Da B, Uhl GR, Snyder SH 1993 Mechanisms of nitric oxide-mediated neurotoxicity in primary brain cultures. J Neurosci 13:2651-2661

19. Dalkara T, Moskowitz MA 1994 The complex role of nitric oxide in the pathophysiology of focal cerebral ischemia. Brain Pathol 4:49-57

20. Trifiletti RR 1992 Neuroprotective effects of $N$-nitro-L-arginine in focal stroke in the 7-day-old rat. Eur J Pharmacol 218:197-198 
21. Hamada X, Hayakawa T, Hattori H, Mikawa H 1994 Inhibition of nitric oxide synthesis reduces hypoxic-ischemic brain damage in the neonatal rat. Pediatr Res $35: 10-14$

22. Mallard EC, Williams CE, Johnston BM, Gunning MI, Davis S, Gluckman PD 1995 Repeated episodes of umbilical cord occlusion in fetal sheep lead to preferential damage to the striatum and sensitize the heart to further insults. Pediatr Res 37:707-713

23. Somjen GG, Aitken PG, Herreras O, Jing J, Young JN 1992 Mechanism of spreading depression: a review of recent findings and a hypothesis. Can J Physiol Pharmacol 70:S248-S254
24. Nedergaard MaH, AJ 1988 Spreading depression is not associated with neuronal injury in the normal brain. Brain Res 449:395-398

25. Simon RP, Niiro M, Gwinn R 1993 Prior ischemic stress protects against experimental stroke. Neurosci Lett 163:135-137

26. Bruno V, Copani A, Battaglia G, Raffaele R, Shinozaki H, Nicoletti F 1994 Protective effect of the metabotropic glutamate receptor agonist, DCG-IV, against excitotoxic neuronal death. Eur J Pharmacol 256:109-112

27. Chiamulera C, Albertini P, Valerio E, Reggiani A 1992 Activation of metabotropic receptors has a neuroprotective effect in a rodent model of focal ischaemia. Eur J Pharmacol 216:335-336 